\title{
Human rights group alleges Bush administration and physicians conducted illegal medical research on detainees
}

Published at www.cmaj.ca on June 28

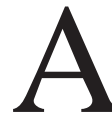

dd another twist to lingering questions from the United

States presidency of George W. Bush about harsh interrogation of detainees after the 9/11 terror attacks of 2001: A doctors' human rights group is alleging that physicians and other medical professionals conducted illegal experimentation on Central Intelligence Agency (CIA) captives during questioning.

A 27-page report by Physicians for Human Rights, based in Cambridge, Massachusetts, draws on heavily redacted US government documents to conclude that medical personnel did more than monitor the detainees, as has been previously reported, and crossed the line into human experimentation by collecting and analyzing data that were then used to refine harsh interrogation techniques, including sleep deprivation and waterboarding, in which water is poured into the breathing passages of captives, causing them to feel as if they are drowning.

The doctors' group joined a coalition of medical and human rights organizations in requesting an investigation by the Office for Human Research Protections, which is responsible for ensuring that federal research complies with US regulations. A government spokeswoman says the office is reviewing the request.

Dr. Allen Keller, a coauthor of the report and program director of the New York City-based Bellevue/New York University Program for Survivors of Torture, says it already was apparent that US health professionals were complicit in torture. Now, he says, "in this report, we present evidence that they also conducted what we believe is unethical and illegal research."

The report, Experiments in Torture: Evidence of Human Subject Research and Experimentation in the 'Enhanced'

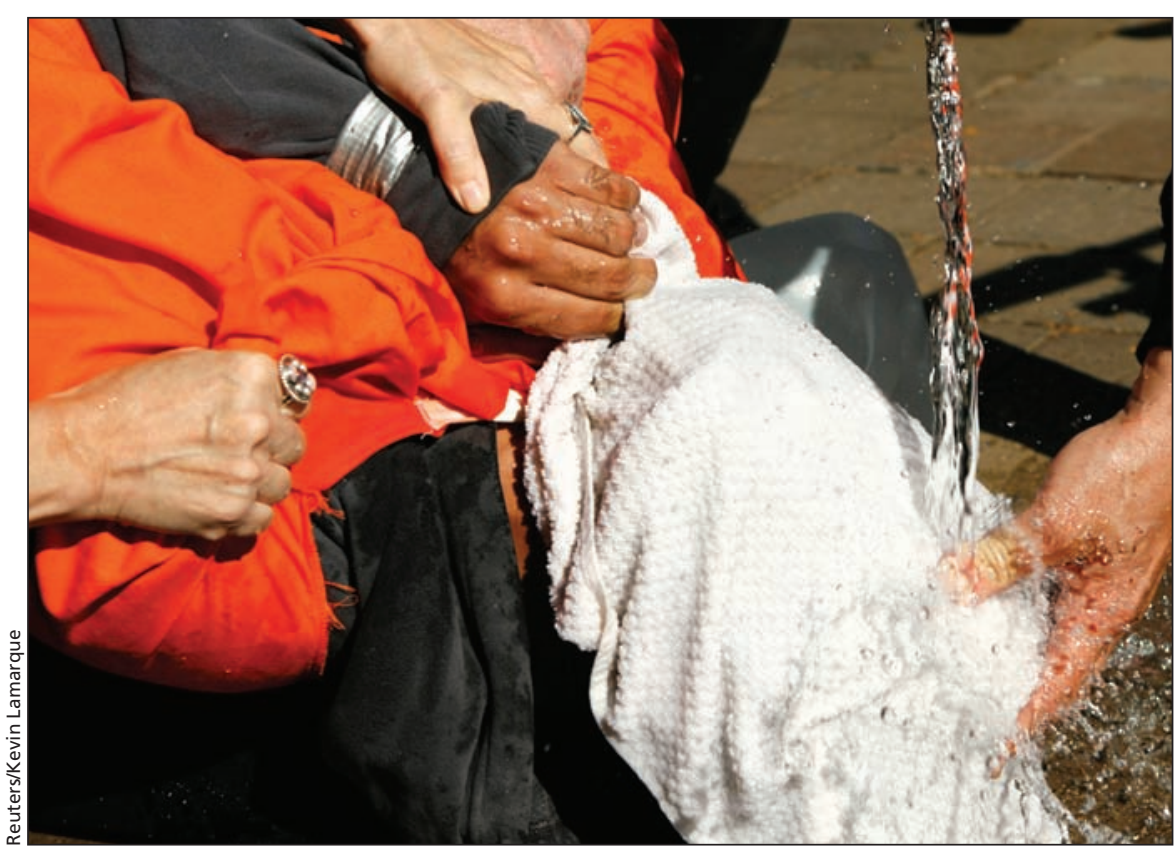

A demonstrator is held down during a simulation of waterboarding outside the Justice Department in Washington, DC.

Interrogation Program, cites three specific examples in which it said health professionals "working for and on behalf of the CIA" engaged in human subject research. It also states that those cases may be only the tip of the iceberg, given that much about the program remains secret.

"The result has been a co-opting of health professionals by the national security apparatus and a violation of the highest medical admonition to "do no harm'," it added.

According to the report:

- Medical personnel monitored all waterboarding of detainees and collected detailed data that was used to revise the simulated drowning tactic. For example, it says, the CIA's Office of Medical Services replaced the use of water with a saline solution, ostensibly to reduce the detainees' risk of contracting pneumonia or hyponatremia, a condition of low sodium levels in the blood.
The report says this would only be medically necessary if someone was being repeatedly subjected to waterboarding and ingesting large amounts of fluid.

- Health professionals observed the interrogation of 25 detainees who were subjected to individual and combined applications of various harsh techniques, and used that information to conclude such piling on of interrogation techniques does not cause more pain. One government memo quoted in the report cited as an example: "When an insult slap is simultaneously combined with water dousing or a kneeling stress position, or when wall standing is simultaneously combined with an abdominal slap and water dousing."

- Health professionals collected observational data on sleep deprivation in increments ranging from 48 hours to 180 hours, and that infor- 
mation was used in shaping policy on future use of the technique.

The report stated that it appears one reason for the experimentation was a belief on the part of government lawyers that investigating the physical and mental consequences of various interrogation techniques could be used as legal cover to fend off charges of torture. In one memo cited in the report, a government lawyer argues that the more investigation undertaken, "the more likely it would be that an interrogator could successfully assert that he acted in good faith and did not intend to inflict severe physical or mental pain or suffering."

CIA spokesman George Little denounced the report as "just wrong," adding: "The CIA did not, as part of its past detention program, conduct human subject research on any detainee or group of detainees."

But California Senator Dianne Feinstein, a Democrat who chairs the Senate Intelligence Committee, says the report's findings will be considered in the com- mittee's ongoing review of the CIA's detention and interrogation program.

While President Barack Obama's administration has been reluctant to investigate allegations of interrogation abuses from the Bush era, human rights advocates say it's important to document past abuses to ensure they aren't repeated and to restore public confidence.

The report points to a March comment by Dennis Blair, then Obama's director of national intelligence, that the administration's interrogation unit would rely on "scientific research" to improve questioning of suspected terrorists. Wendy Morigi, a spokeswoman for the intelligence office, said Blair "was in no way suggesting research on the detainees themselves." Rather, she said, the interrogation unit would "look at scientific research that would allow for refinement of current best practices."

Nancy Berlinger, a research scholar at the Hastings Center, a bioethics research institution based in Garrison, New York, calls the findings "sadden- ing as well as shocking," and notes that current limitations on human subject research in many countries are an outgrowth of revelations about experimentation in World War II concentration camps and on prisoners of war.

Further investigation is needed, she says, because "we need to understand how the goals of professions can be undermined. We need to understand how complicity takes place" to ensure that safeguards prevent a reoccurrence.

Steven Soldz, president-elect of the nonprofit group Psychologists for Social Responsibility, says it's important to investigate the allegations further to maintain public trust in medical research. "If people are not convinced that researchers are going to act for their good, they're not going to enrol in studies and they're not going to support research through tax dollars," he says. "The whole research enterprise depends on trust among the populace." — Nancy Benac, Washington, DC

DOI:10.1503/cmaj.109-3299 